doi: $10.2306 /$ scienceasia1513-1874.2013.39.384

\title{
A feasibility study of oil content and fatty acid composition of seed powder and seed oil of Pongamia pinnata by near infrared spectroscopy
}

\author{
Chutarat Khamchum $^{\mathrm{a}}$, Vittaya Punsuvon ${ }^{\mathrm{a}, \mathrm{b}, \mathrm{c}, *}$, Sumaporn Kasemsumran ${ }^{\mathrm{d}}$, \\ Nattaporn Suttiwijitpukdee ${ }^{\mathrm{d}}$ \\ ${ }^{a}$ Department of Chemistry, Faculty of Science, Kasetsart University, Bangkok 10900 Thailand \\ b Centre of Excellence-Oil Palm, Kasetsart University, Bangkok 10900 Thailand \\ c Centre of Advanced Studies in Tropical Natural Resource, NRU-KU, Kasetsart University, \\ Bangkok 10900 Thailand \\ ${ }^{\mathrm{d}}$ Kasetsart Agricultural and Agro-Industrial Product Improvement Institute (KAPI), Kasetsart University, \\ Bangkok 10900 Thailand
}

*Corresponding author, e-mail: fscivit@ku.ac.th

Received 6 Nov 2012

Accepted 17 May 2013

\begin{abstract}
Near infrared reflectance spectroscopy (NIRS) coupled with a geometric study was used to estimate the oil content and fatty acid composition of Pongamia pinnata seed powder and seed oil. Sixty seed powders and seed oils from various sources of $P$. pinnata in southern Thailand were scanned by NIRS. All samples were analysed for oil content by hexane extraction and fatty acid composition by gas chromatography. Calibration equations were developed for oil content and individual fatty acids (palmitic acid C16:0, stearic acid C18:0, oleic acid C18:1, linoleic acid C18:2, and behenic acid C22:0). The results showed that NIRS was a reliable and accurate technique to estimate oil content from seed powder, as well as the concentrations of oleic, behenic, and linoleic acid in seed oil. Screening by NIRS of $P$. pinnata seed powders and seed oils represents a rapid, simple, and cost-effective alternative method that may be of great utility for analysing a large number of seed samples for tree breeding and plantations for the biofuel industry.
\end{abstract}

KEYWORDS: non-destructive method, partial least square regression, oil properties, biofuels

\section{INTRODUCTION}

Pongamia pinnata belongs to the family Leguminosae. It is a medium sized glabrous tree that generally attains a height of about $18 \mathrm{~m}$ and a trunk diameter $>50 \mathrm{~cm}$. It can grow under a wide range of agroclimatic conditions and is a common sight around coastal areas, riverbanks, tidal forest, and roadsides. $P$. pinnata can grow in soil types ranging from stony to sandy to clayey, including verticals. It is highly tolerant of salinity and can be propagated either by seed or by root suckers ${ }^{1}$. In Thailand, $P$. pinnata is commonly known as 'hye nam' or 'hye talay'. After 5-7 years of growth, it bears fruits containing one to two kidney-shaped brownish-red kernels. P. pinnata is one of a few nitrogen-fixing trees that can produce seed kernels containing $18-27 \%$ oil $^{2}$. The advantages of $P$. pinnata are dominantly powerful. All parts of the plant possibly can be used as a herb for the treatment of tumours, piles, skin diseases, itches, abscess, painful rheumatic joints wounds, ulcers, and diarrhoea $^{3}$. P. pinnata oil also finds use in the cosmetic field as a raw material in the soap and leathertanning industries. Among the excellent benefit, the freshly extracted oil also contains toxic flavonoids such as karanjin, pongapin, and pongaglubin, making it an inedible oil ${ }^{4}$. P pinnata oil is regarded as a potential fuel substitute that contains 16-22 carbon atoms per molecule. Hence $P$. pinnata oil has the potential to become a raw material for the conversion to methyl esters or biodiesel ${ }^{1}$. With the growing interest in the seed oil of $P$. pinnata for biodiesel production, collection and characterization has been undertaken. The aim is to develop it as a profitable crop for future biodiesel production in Thailand. The identification of target traits often involves the evaluation of a large number of seed samples and the current standard screening methods for oil content and fatty acid composition seem to be less suitable in this respect since they are labour-intensive, time consuming, and destroy the samples.

A rapid, non destructive, and inexpensive analyt- 
ical method would be more preferable for large scale screening. Near infrared spectroscopy (NIRS), one of the most reliable multitraits evaluating techniques in agricultural and food analysis, meets these requirements. In case of seed sample, NIRS can be used to analyse a large number of seed samples in small quantities in the form of whole grain or powder. NIRS calibration relies on wet chemistry determination. The laboratory uncertainty is one of the error sources of NIRS which leads to equations that cannot predict the contents of the sample with high accuracy and precision ${ }^{5}$. NIRS has been applied to fatty acid profiling in oil seeds including rapeseed ${ }^{6}$, peanut ${ }^{7}$, sesame $^{8}$, sheanut ${ }^{9}$, and Jatropha curcas ${ }^{10}$. It has also been used to study oil content in cotton seed ${ }^{11}$.

Another research by Vaknin et $\mathrm{al}^{10}$ used NIRS to develop a quick and nondestructive method to estimate the oil content, fatty acid composition (palmitic acid C16:0, stearic acid C18:0, oleic acid C18:1, and linoleic acid C18:2), and protein content of $\mathrm{Ja}$ tropha curcas seeds and to apply the novel technique to analyse $J$. curcas seeds of various origins, from breeding programs to commercial plantations. Balabin and Safieva ${ }^{12}$ found a correlation between the near infrared spectrum of a biodiesel sample and its feedstock. The correlation was used to classify samples into 10 groups correctly according to their origins (a type of vegetable oil). Principal component analysis was used to detect outliers and to reduce dimensionality of NIR spectral data. Four different multivariate data analysis techniques were used to solve the problem, including regularized discriminant analysis, partial least square method (PLS), K-nearest neighbours (KNN) technique, and support vector machines (SVMs). KNN and SVMs methods were found to be highly effective for biodiesel classification by feedstock oil type. Baptista et $\mathrm{al}^{13}$, reported the use of NIR spectroscopy to determine the ester content in biodiesel, which is one of its main properties. In fact, the ester content is an indicator of the degree of conversion of the transesterification reaction. NIR spectroscopy can also be used to determine the composition of biodiesel in the main methyl ester (palmitic acid C16:0, stearic acid C18:0, oleic acid C18:1, linoleic acid C18:2, and linolenic acid C18:3). However, it is not known whether NIR can be applied to determine the oil content and fatty acid profile of P. pinnata seed.

The objectives of this study are to apply NIRS technique for the comparison of oil content and fatty acid composition in the seed powder and seed oil of $P$. pinnata collected from southern Thailand, and to develop the prediction models for oil content and fatty acid composition. This is the first application of NIRS technique to P. pinnata. In this study, the different spectral pretreatment techniques combined with the partial least squares analysis were introduced to develop statistical models in terms of calibration equation for each value.

\section{MATERIALS AND METHODS}

\section{Seed powder}

Exploration trips were conducted during the months of January-May 2011 in various districts of Ranong, Phung-Nga, Krabi provinces and 60 samples were collected. Representative samples consisting of 2$3 \mathrm{~kg}$ pods covering all sides of the selected tree were collected. Pods were stored at room temperature. For seed oil content and fatty acid composition analyses, one kilogram of pods were randomly picked up from this lot. The pod hulls were manually removed to obtain seed kernels, which were then ground by grinder (Moulinex, type NE401, France) and sizing with a sieve (40-60 mesh) to obtain meals or seed powder. The final sample was randomly drawn from this powder for the experiment. The picture of seed kernels and seed powder of $P$. pinnata were shown in Fig. 1. All other chemicals used were of analytical grade.

\section{Oil extraction}

Oil content in P. pinnata seed powder was quantitated using a Soxhlet extraction method. Seed powder $(15 \mathrm{~g})$ was extracted using hexane $(200 \mathrm{ml})$ as a solvent at $70^{\circ} \mathrm{C}$ for $4 \mathrm{~h}$ in Soxhlet extractor (Buchi, Switzerland). After $4 \mathrm{~h}$, the solvent was evaporated using a rotary evaporator and the remaining yellow oil was weighed for determination of oil content. All analysis were performed in duplicates.

\section{Fatty acid composition analysis}

The methylation of the extracted oil was performed by reacting with boron trifluoride/methanol, and then the solution was treated with $\mathrm{KOH} /$ methanol as described by AOAC 969.3 official method. These fatty acid methyl esters were identified and separated by gas chromatography (GC) using an Agilent 6890 Gas Chromatograph (Agilent Technologies) equipped with a flame ionization detector and a $30 \mathrm{~m} \times 0.32 \mathrm{~mm}$ (i.d.) fused siloxane capillary column (DB-WAX 127$7012,0.25 \mu \mathrm{m}$ film thickness). Oven temperature was maintained at $110^{\circ} \mathrm{C}$ for $5 \mathrm{~min}$, and then increased to $200{ }^{\circ} \mathrm{C}$ at $5{ }^{\circ} \mathrm{C} / \mathrm{min}$. Injector and detector temperatures were $210^{\circ} \mathrm{C}$ and $250^{\circ} \mathrm{C}$, respectively. Helium was the carrier gas at a split ratio of 30:1 and a constant flow 


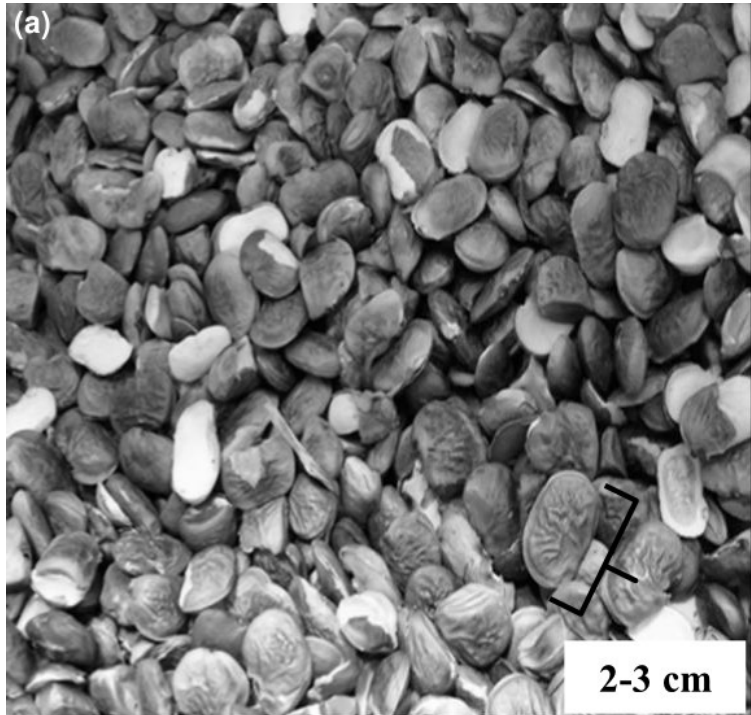

(b)

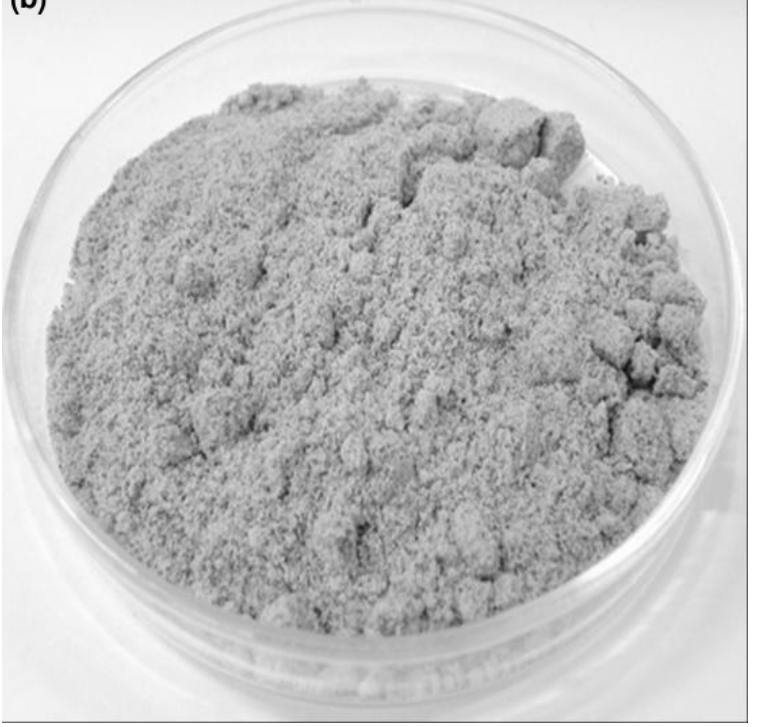

Fig. 1 Pongamia pinnata (a) seed kernels and (b) seed powder.

rate of $1.0 \mathrm{ml} / \mathrm{min}$. Fatty acid peaks were identified by comparing retention times with known fatty acid methyl ester standards (Sigma-Aldrich Chemie). The quantification of each fatty acid was performed by internal normalization method.

\section{NIRS scanning: seed powder and seed oil}

NIRS technique was used to analyse the properties of $P$. pinnata seed powder and seed oil. The transflection mode were applied to all measurements. Seed powder samples were placed in a powder cup with multicup adapter. The NIRS spectra were collected in the region of $1100-2500 \mathrm{~nm}$ by near infrared spec- trophotometer (Unity, Spectrastar). In the case of seed oil samples, a liquid cell with a gold cover was used to optimize the best spectral condition. Both the seed powder and seed oil were scanned twice and the reflectance spectra $(\log 1 / R)$ were recorded at $1 \mathrm{~nm}$ intervals. All spectral and calibrations were conducted with the Unscrambler 9.8 (Camo) software.

\section{NIR spectral pretreatment and calibration}

NIR calibration equations were developed for oil content, palmitic acid (C16:0), stearic acid (C18:0), oleic acid (C18:1), linoleic acid (C18:2), and behenic acid (C22:0). Savitzky-Golay first derivative (1De) and second derivative (2De) were combined with other techniques such as smoothing (SM), normalize (NM) to transform spectra, in order to overcome distortions. The Range Normalization: NM-range was calculated by $A_{\lambda, \mathrm{NM}}=A_{\lambda} /\left(A_{\lambda, \max }-A_{\lambda, \min }\right)$, where $A$ is absorbance at wavelength $\lambda$.

Calibration equations were developed based on the treated spectral data by application of partial least squares regression with Unscrambler 9.8 (Camo). The ability to predict the properties of 15 randomly chosen external samples by means of calibration equations based on the remaining population of 45 samples were assayed by external validation. The correlation coefficient of determination $\left(R^{2}\right)$, the standard error of calibration (SECV), the standard error of prediction (SEP) of external validation, and bias served as indicators of prediction quality. Optimum calibration equations were obtained based on the highest $R^{2}$ and the lowest SECV or SEP values. The standard deviation over standard error of prediction (SD/SEP) ratio which was referred as relative predictive determination $\left(\mathrm{RPD}_{\mathrm{p}}\right)$ in prediction set was used to evaluate the accuracy of calibration equation.

\section{RESULTS AND DISCUSSION}

\section{Fatty acid composition}

The retention time of palmitic acid (C16:0), stearic acid (C18:0), oleic acid (C18:1), linoleic acid (C18:2), and behenic acid (C22:0) were at 12.82, 14.60, $14.78,15.17$, and $17.78 \mathrm{~min}$, respectively. The chromatogram of fatty acid compositions of oil extracted from seed is shown in Fig. 2.

It was found that more than five fatty acids could be identified in Thai P. pinnata oil which was largely different from Indian $P$. pinnata oil ${ }^{14}$. Only four fatty acids as palmitic, stearic, oleic and linoleic acids were present while behenic acid was not detected. The difference in fatty acid composition may be attributed to the geographical location. In this work, five fatty 


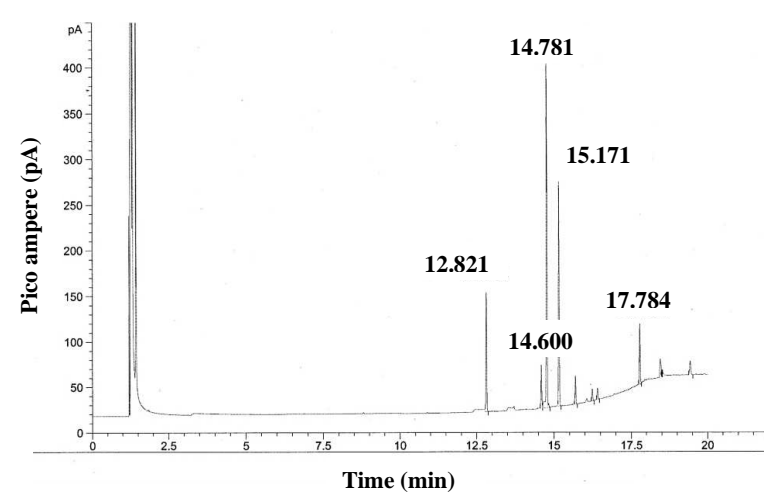

Fig. 2 Chromatogram of fatty acid composition in P. pinnata oil.

Table 1 The range value of each composition in calibration and prediction set.

\begin{tabular}{lcc}
\hline Composition & \multicolumn{2}{c}{ Content $(\% \mathrm{w} / \mathrm{w})$} \\
\cline { 2 - 3 } & Calibration set & Prediction set \\
\hline Oil content & $23.5-32.6$ & $25.1-32.2$ \\
Palmitic acid & $10.4-15.7$ & $10.9-15.6$ \\
Stearic acid & $2.7-13.9$ & $3.0-8.8$ \\
Oleic acid & $35.0-50.6$ & $35.0-50.5$ \\
Linoleic acid & $10.0-26.9$ & $10.2-26.9$ \\
Behenic acid & $4.1-12.9$ & $5.4-12.9$ \\
\hline
\end{tabular}

acids as palmitic, stearic, oleic, linoleic, and behenic acids were quantified by GC and estimated by NIRS.

The range of oil and individual fatty acid contents in the calibration (45 samples) and prediction sets (15 samples) were determined. The range value of each component in calibration and prediction set is shown in Table 1.

These results showed that the largest content range was linoleic acid followed by oleic, behenic, and stearic acids. Palmitic acid was within the smallest content range. High amount of unsaturated fatty acid as oleic (C18:1) and linoleic acids (C18:2) indicated that $P$. pinnata oil is very useful for biodiesel production.

\section{Spectral analysis}

The original NIR spectra of all powder sample (45 samples) between 1100 and $2500 \mathrm{~nm}$ of wavelength is shown in Fig. 3. The average spectra of powder samples had maximum absorption bands at $1210,1470,1720,1760,1935,2140,2300$, and $2348 \mathrm{~nm}$. These were similar to the wavelengths of absorption bands reported by Pérez-Vich, et al ${ }^{15}$ who determined the contents of oil and fatty acid in sunflower seed, meal and oil by the NIRS technique.

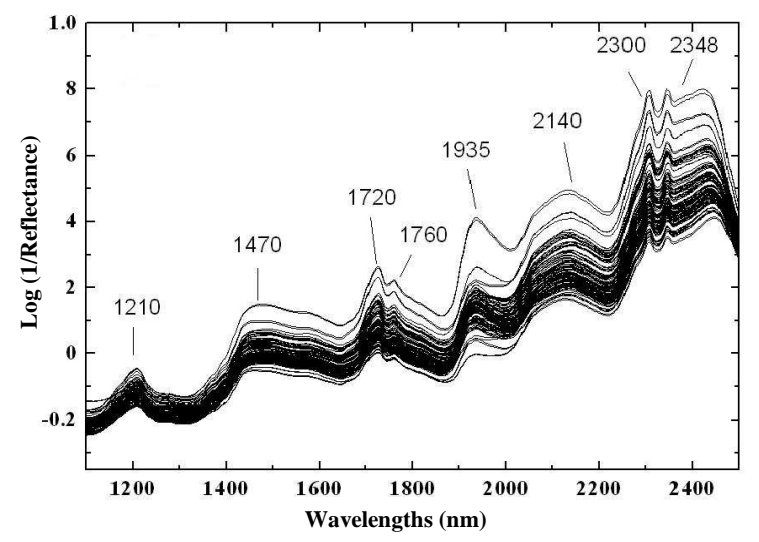

Fig. 3 The original NIRS spectra of all P. pinnata seed powder samples.

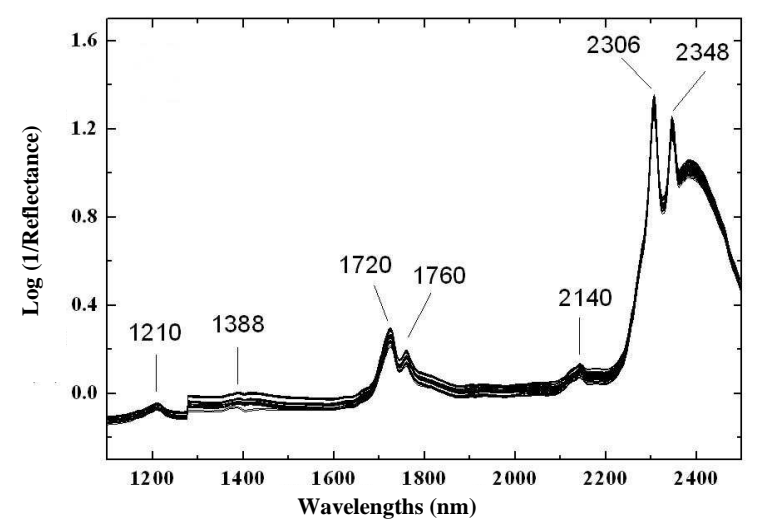

Fig. 4 The original NIRS spectra of 60 P. pinnata seed oil samples.

The original NIRS spectra of oil (45 samples) between 1100 and $2500 \mathrm{~nm}$ of wavelength are shown in Fig. 4. The average spectra of oil sample had maximum absorption bands at 1210, 1388, 1720, 1760, 2140, 2306, and $2348 \mathrm{~nm}$. The bands at $1210 \mathrm{~nm}$ were assigned to the second overtone of $\mathrm{C}-\mathrm{H}$ stretching mode, those at $1388-1470 \mathrm{~nm}$ were assigned to the first overtone of $\mathrm{C}-\mathrm{H}$ combination modes, those at $1720-1760 \mathrm{~nm}$ were assigned to the first overtone of $\mathrm{C}-\mathrm{H}$ stretching modes, those at $1935-2140 \mathrm{~nm}$ were associated with the second overtone of $\mathrm{C}=\mathrm{O}$ stretching and the combination of $\mathrm{C}-\mathrm{C}$ mode, and those at 2300-2348 nm were associated with the combination band of $\mathrm{C}-\mathrm{H}$ symmetric and anti-symmetric stretching modes ${ }^{16}$.

Both NIRS spectra had a similar trend but powder samples had more absorption bands than oil samples. Fig. 3 and Fig. 4 show broad spectra, so a mathemat- 
Table 2 Comparative statistical results obtained from the model built by using different spectral pretreatment techniques in the range of $1100-2500 \mathrm{~nm}$ of seed powder samples.

\begin{tabular}{|c|c|c|c|c|c|c|}
\hline \multirow[t]{2}{*}{ Composition } & \multirow[t]{2}{*}{ Pretreatment $^{\dagger}$} & \multicolumn{5}{|c|}{ Calibration $^{\ddagger}$} \\
\hline & & $\mathrm{F}$ & $R^{2}$ & SECV & Bias & $\mathrm{RPD}_{\mathrm{c}}$ \\
\hline \multirow[t]{4}{*}{ Oil content } & $\mathrm{SM}+1 \mathrm{De}(5)$ & 8 & 0.84 & 0.78 & -0.02 & 2.5 \\
\hline & $\mathrm{NM}+1 \mathrm{De}(5)$ & 7 & 0.86 & 0.73 & -0.013 & 2.6 \\
\hline & $\mathrm{SM}+2 \mathrm{De}(5)$ & 3 & 0.74 & 1.0 & -0.028 & 1.9 \\
\hline & $\mathrm{NM}+2 \mathrm{De}(5)$ & 6 & 0.71 & 1.06 & -0.007 & 1.8 \\
\hline \multirow[t]{4}{*}{ Palmitic acid } & $\mathrm{SM}+1 \mathrm{De}(25)$ & 7 & 0.39 & 1.25 & 0.025 & 1.0 \\
\hline & $\mathrm{NM}+1 \mathrm{De}(25)$ & 9 & 0.38 & 1.27 & 0.008 & 1.0 \\
\hline & $\mathrm{SM}+2 \mathrm{De}(25)$ & 4 & 0.25 & 1.39 & 0.002 & 0.9 \\
\hline & $\mathrm{NM}+2 \mathrm{De}(25)$ & 8 & 0.28 & 1.36 & -0.01 & 0.9 \\
\hline \multirow[t]{4}{*}{ Stearic acid } & $\mathrm{SM}+1 \mathrm{De}(21)$ & 11 & 0.39 & 1.2 & 0.026 & 1.5 \\
\hline & $\mathrm{NM}+1 \mathrm{De}(21)$ & 15 & 0.36 & 1.22 & 0.006 & 1.5 \\
\hline & $\mathrm{SM}+2 \mathrm{De}(21)$ & 13 & 0.30 & 1.28 & 0.021 & 1.4 \\
\hline & $\mathrm{NM}+2 \mathrm{De}(21)$ & 13 & 0.36 & 1.24 & -0.015 & 1.5 \\
\hline \multirow[t]{3}{*}{ Oleic acid } & SM & 10 & 0.63 & 2.5 & 0.006 & 1.5 \\
\hline & $\mathrm{NM}+1 \mathrm{De}(21)$ & 19 & 0.56 & 2.75 & 0.113 & 1.3 \\
\hline & $\mathrm{NM}+2 \mathrm{De}(21)$ & 16 & 0.64 & 2.49 & 0.126 & 1.5 \\
\hline \multirow[t]{4}{*}{ Linoleic acid } & SM + 1De (21) & 8 & 0.49 & 2.86 & -0.008 & 1.4 \\
\hline & $\mathrm{NM}+1 \mathrm{De}(21)$ & 10 & 0.52 & 2.77 & 0.068 & 1.4 \\
\hline & $\mathrm{SM}+2 \mathrm{De}(21)$ & 6 & 0.46 & 2.95 & -0.026 & 1.3 \\
\hline & $\mathrm{NM}+2 \mathrm{De}(21)$ & 7 & 0.49 & 2.87 & 0.001 & 1.4 \\
\hline \multirow[t]{4}{*}{ Behenic acid } & SM + 1De (23) & 12 & 0.55 & 1.21 & 0.05 & 1.5 \\
\hline & $\mathrm{NM}+1 \mathrm{De}(23)$ & 12 & 0.60 & 1.15 & 0.032 & 1.6 \\
\hline & $\mathrm{SM}+2 \mathrm{De}(23)$ & 7 & 0.51 & 1.27 & -0.001 & 1.4 \\
\hline & $\mathrm{NM}+2 \mathrm{De}(23)$ & 8 & 0.52 & 1.26 & -0.001 & 1.4 \\
\hline
\end{tabular}

SM: smoothing, 1De: first derivatives Savitsky-Golay, 2De: second derivatives Savitsky-Golay, NM: normalize.

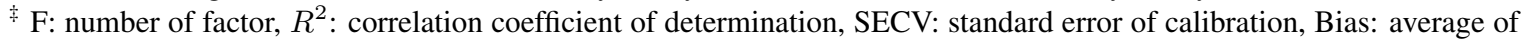
differences between reference value and NIR value, $\mathrm{RPD}_{\mathrm{c}}$ : relative of predicted determinant of calibration $(\mathrm{SD} / \mathrm{SECV})$.

ical transformation needs to be applied to produce a narrow band. In our work, the transformation with first derivatives (1De) and second derivatives (2De) were used as pretreatment to process original spectra of powder samples. The overall narrow absorption bands in first and second derivatives spectra were used to determine oil and fatty acid contents.

In developing NIRS model for oil content and fatty acid composition analysis, different pretreatment technique combined with first and second derivative spectra and partial least square analysis were applied to get the accurate model. The effects of different pretreatment techniques in powder and oil are presented in Table 2 and Table 3, respectively. The best NIRS calibration was characterized by small value of SECV and Bias and large $R^{2}$ and RPD value. Information from Tables 2 and 3 showed high potential for determining oil content and fatty acid compositions by a combination technique with Savitsky-Golay first derivative. The summary of selected pretreatment techniques for each composition analysis is shown in Table 4.
The optimum calibration model was selected based on the low standard error of calibration (SECV), low bias value, high the correlation coefficient of determination $\left(R^{2}\right)$ and high relative predictive determination (RPD). Table 4 shows the calibration of oil content with highest correlation coefficient of calibration $\left(R^{2}=0.86\right)$. For fatty acid compositions, oleic acid gave the highest correlation coefficient of calibration $\left(R^{2}=0.74\right)$, followed by stearic acid $\left(R^{2}=0.69\right)$, linoleic acid $\left(R^{2}=0.62\right)$, behenic acid $\left(R^{2}=0.60\right)$, and palmitic acid $\left(R^{2}=0.48\right)$. Most fatty acid compositions which were determined in oils have higher $R^{2}$ and lower error (SECV) than those in powder except behenic acid.

\section{External prediction}

The predicted statistics for oil content and fatty acid composition are shown in Table 4. The prediction statistics included correlation coefficient $\left(R^{2}\right)$, standard error of prediction (SEP), relative of the predictive determinant of calibration $\left(\mathrm{RPD}_{\mathrm{p}}\right)$ or $\mathrm{SD} / \mathrm{SEP}$ values, which were factors used to evaluate the reli- 
Table 3 Comparative statistical results obtained from the model built by using different spectral pretreatment techniques in the range of 1100-2500 $\mathrm{nm}$ of seed oil samples.

\begin{tabular}{|c|c|c|c|c|c|c|}
\hline \multirow[t]{2}{*}{ Composition } & \multirow[t]{2}{*}{ Pretreatment $^{\dagger}$} & \multicolumn{5}{|c|}{ Calibration } \\
\hline & & $\mathrm{F}$ & $R^{2}$ & SECV & Bias & $\mathrm{RPD}_{\mathrm{c}}$ \\
\hline \multirow[t]{4}{*}{ Palmitic acid } & $\mathrm{SM}+1 \mathrm{De}(25)$ & 10 & 0.5 & 0.93 & -0.0 & 1.4 \\
\hline & $\mathrm{NM}+1 \mathrm{De}(25)$ & 10 & 0.5 & 0.93 & -0.0 & 1.4 \\
\hline & $\mathrm{SM}+2 \mathrm{De}(25)$ & 8 & 0.4 & 0.96 & 0.01 & 1.3 \\
\hline & $\mathrm{NM}+2 \mathrm{De}(25)$ & 8 & 0.4 & 1.03 & 0.013 & 1.2 \\
\hline \multirow[t]{4}{*}{ Stearic acid } & $\mathrm{SM}+1 \mathrm{De}(21)$ & 12 & 0.7 & 1.04 & 0.003 & 1.7 \\
\hline & $\mathrm{NM}+1 \mathrm{De}(21)$ & 13 & 0.7 & 1.02 & 0.0 & 1.8 \\
\hline & $\mathrm{SM}+2 \mathrm{De}(21)$ & 4 & 0.6 & 1.17 & -0.02 & 1.5 \\
\hline & $\mathrm{NM}+2 \mathrm{De}(21)$ & 4 & 0.6 & 1.16 & -0.01 & 1.6 \\
\hline \multirow[t]{3}{*}{ Oleic acid } & SM & 12 & 0.7 & 1.89 & 0.033 & 1.9 \\
\hline & $\mathrm{NM}+1 \mathrm{De}(21)$ & 11 & 0.7 & 2.11 & -0.02 & 1.7 \\
\hline & $\mathrm{NM}+2 \mathrm{De}(21)$ & 10 & 0.6 & 2.25 & 0.081 & 1.6 \\
\hline \multirow[t]{4}{*}{ Linoleic acid } & SM + 1De (21) & 12 & 0.6 & 2.46 & -0.02 & 1.6 \\
\hline & $\mathrm{NM}+1 \mathrm{De}(21)$ & 12 & 0.6 & 2.46 & -0.03 & 1.7 \\
\hline & $\mathrm{SM}+2 \mathrm{De}(21)$ & 9 & 0.6 & 2.51 & -0.02 & 1.6 \\
\hline & $\mathrm{NM}+2 \mathrm{De}(21)$ & 7 & 0.6 & 2.53 & -0.01 & 1.6 \\
\hline \multirow[t]{4}{*}{ Behenic acid } & $\mathrm{SM}+1 \mathrm{De}(23)$ & 12 & 0.6 & 1.17 & -0.02 & 1.5 \\
\hline & $\mathrm{NM}+1 \mathrm{De}(23)$ & 11 & 0.6 & 1.18 & -0.02 & 1.5 \\
\hline & $\mathrm{SM}+2 \mathrm{De}(23)$ & 15 & 0.6 & 1.17 & 0.018 & 1.5 \\
\hline & $\mathrm{NM}+2 \mathrm{De}(23)$ & 10 & 0.5 & 1.24 & 0.029 & 1.4 \\
\hline
\end{tabular}

SM: smoothing, 1De: first derivatives Savitsky-Golay, 2De: second derivatives Savitsky-Golay, NM: normalize.

$\$$ F: number of factor, $R^{2}$ : correlation coefficient of determination, SECV: standard error of calibration, Bias: average of differences between reference value and NIR value, $\mathrm{RPD}_{\mathrm{c}}$ : relative of predicted determinant of calibration $(\mathrm{SD} / \mathrm{SECV})$.

Table 4 Summary of pretreatment techniques, monitoring statistics in calibration model and external prediction in wavelength 1100-2500 $\mathrm{nm}$ of seed powder and seed oil samples.

\begin{tabular}{|c|c|c|c|c|c|c|c|c|c|c|}
\hline \multirow[t]{2}{*}{ Composition } & \multirow[t]{2}{*}{ Type } & \multirow[t]{2}{*}{ Pretreatment } & \multirow[t]{2}{*}{$\mathrm{F}$} & \multicolumn{3}{|c|}{ Calibration } & \multicolumn{4}{|c|}{ Prediction } \\
\hline & & & & $R^{2}$ & SECV & Bias & $R^{2}$ & SEP & SD & $\mathrm{RPD}_{\mathrm{p}}$ \\
\hline Oil content & $\mathrm{P}$ & $\mathrm{NM}+1 \mathrm{De}(5)$ & 7 & 0.9 & 0.73 & -0.01 & 0.7 & 1.0 & 1.9 & 1.9 \\
\hline Palmitic acid & $\mathrm{O}$ & $\mathrm{NM}+1 \mathrm{De}(25)$ & 10 & 0.5 & 0.93 & -0.0 & 0.6 & 0.9 & 1.4 & 1.5 \\
\hline Palmitic acid & $\mathrm{P}$ & SM + 1De (25) & 7 & 0.4 & 1.25 & 0.025 & 0.5 & 1.1 & 1.6 & 1.4 \\
\hline Stearic acid & $\mathrm{O}$ & $\mathrm{NM}+1 \mathrm{De}(21)$ & 13 & 0.7 & 1.02 & 0.0 & 0.4 & 0.9 & 1.2 & 1.2 \\
\hline Stearic acid & $\mathrm{P}$ & $\mathrm{SM}+1 \mathrm{De}(21)$ & 11 & 0.4 & 1.2 & 0.026 & 0.6 & 1.3 & 1.9 & 1.5 \\
\hline Oleic acid & $\mathrm{O}$ & SM & 12 & 0.7 & 1.89 & 0.033 & 0.7 & 2.0 & 3.8 & 1.9 \\
\hline Oleic acid & $\mathrm{P}$ & $\mathrm{NM}+2 \mathrm{De}(21)$ & 16 & 0.6 & 2.49 & 0.126 & 0.7 & 2.0 & 3.8 & 1.9 \\
\hline Linoleic acid & $\mathrm{O}$ & $\mathrm{NM}+1 \mathrm{De}(21)$ & 12 & 0.6 & 2.46 & -0.03 & 0.7 & 2.2 & 4 & 1.8 \\
\hline Linoleic acid & $\mathrm{P}$ & $\mathrm{NM}+1 \mathrm{De}(21)$ & 10 & 0.5 & 2.77 & 0.068 & 0.6 & 2.6 & 4 & 1.5 \\
\hline Behenic acid & $\mathrm{O}$ & $\mathrm{SM}+1 \mathrm{De}(23)$ & 12 & 0.6 & 1.17 & -0.02 & 0.6 & 1.1 & 1.8 & 1.7 \\
\hline Behenic acid & $\mathrm{P}$ & $\mathrm{NM}+1 \mathrm{De}(23)$ & 12 & 0.6 & 1.15 & 0.032 & 0.7 & 1.0 & 1.8 & 1.7 \\
\hline
\end{tabular}

P: powder, O: oil, SM: smoothing, 1De: first derivatives Savitsky-Golay, 2De: second derivatives Savitsky-Golay, NM: normalize, F: number of factor, $R^{2}$ : correlation coefficient of determination, SECV: standard error of calibration, Bias: average of differences between reference value and NIR value, SEP: standard error of prediction, SD: standard deviation, $\mathrm{RPD}_{\mathrm{p}}$ : relative of predictive determinant of calibration $(\mathrm{SD} / \mathrm{SEP})$.

ability of the calibration model. The standard error of prediction (SEP) of fatty acid compositions of the oil are lower than those in powder, except oleic and behenic acids, that have an SEP in powder better than in oil in minimal values. The $\mathrm{RPD}_{\mathrm{p}}$ values of palmitic and stearic acids ( 1.5 and 1.5 , respectively), indicated a poor correlation between reference and NIRS estimated values. The prediction for the contents of oil, oleic acid, linoleic acid, and behenic acid were confirmed by the higher values of $R^{2}(0.73,0.70,0.69$, 

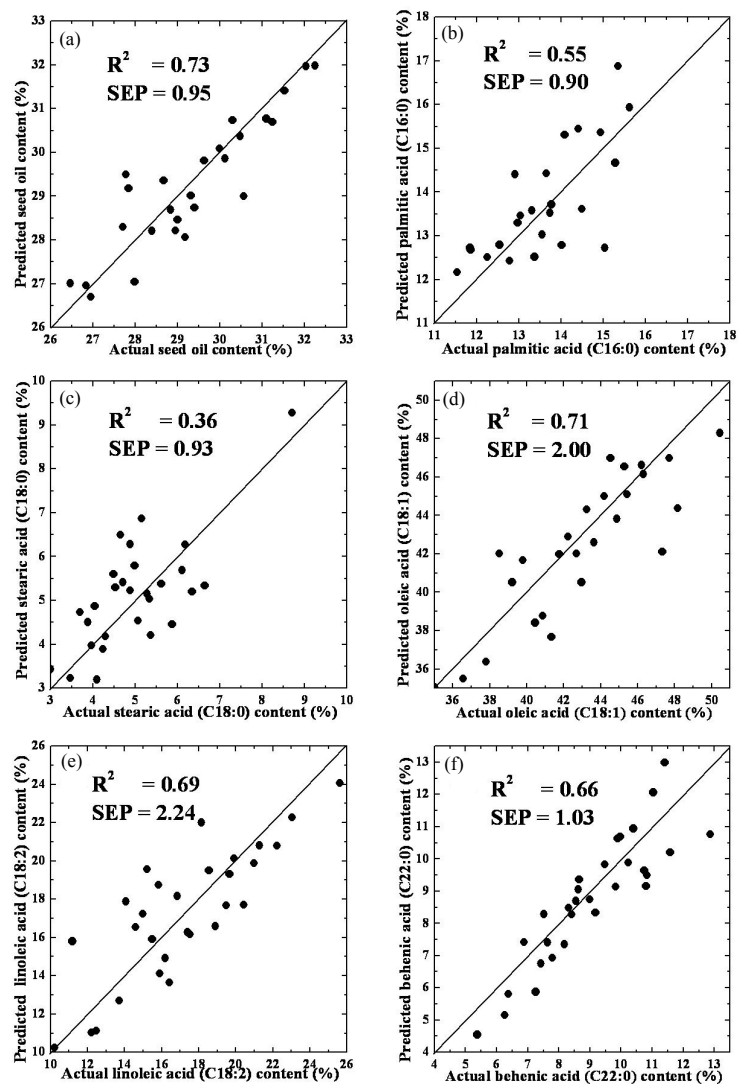

Fig. 5 Correlation plots between the predicted and actual values; (a) oil content, (b) palmitic acid in oil, (c) stearic acid in oil, (d) oleic acid in powder, (e) linoleic acid in oil, and (f) behenic acid in powder.

and 0.66 , respectively) and $\operatorname{RPD}_{\mathrm{p}}(1.9,1.9,1.8$, and 1.7 , respectively). The $\mathrm{RPD}_{\mathrm{p}}$ value as the cut off point for evaluating the accuracy of equations was above 1.5 for this study, which was recommended for reliable prediction (for rough screening) ${ }^{5}$.

Fig. 5 shows laboratory reference values against NIRS predicted values in the prediction set for oil content and individual fatty acid compositions. These results demonstrate the accurate prediction capacities of the calibration model for the contents of oil, oleic acid, linoleic acid, and behenic acid using a nondestructive NIRS method in P. pinnata seed powder and oil. The broad ranges of these compositions were the reasons that made all of these models had accurate prediction. Since palmitic and stearic acids had narrow range, so the prediction models were less accurate. The less accuracy of palmitic and stearic acid estimates could be addressed by increasing the number and broader range of reference samples.

The correlation coefficient of $P$. pinnata oil and powder was similar to the report of Vaknin et al ${ }^{10}$ who estimated oil content and fatty acid composition in J. curcas seed using NIRS with seventy four intact ground kernel samples. Vaknin reported a reliable estimation only for the contents of oil and linoleic acid because of their high coefficient correlations $\left(R^{2}=\right.$ $0.78,0.73$, respectively). Another result on palmitic, stearic, and oleic acids had low $R^{2}$ value $(0.10,0.15$, 0.52 , respectively). The results also indicated that oil sample for NIRS analysis gave accurate model than ground kernel sample. For oil content, both works showed that ground kernel or powder could be used as an intact sample to obtain accurate predicting model. In the future work, we will only use oil content predicting model obtained from this study for screening oil content in an intact powder of $P$. pinnata for tree breeding and plantation program.

\section{CONCLUSIONS}

It is concluded that the determination of the contents of oil, oleic, linoleic, and behenic acids in seed oil and powder of $P$. pinnata can be predicted with reliable accuracy using NIRS analysis. The presence of larger population of $P$. pinnata covering a wide range chemical values was required to obtain the accurate prediction of palmitic and stearic acids. Seed oil analysis provided more accurate results than seed powder analysis. Thus the NIRS method can be used to simplify the analysis of oil content and fatty acid composition because extraction steps with organic solvent is not required and instrumental analysis can be completed within a few minutes. In addition, NIRS method can replace chromatographic method such as GC in fatty acid composition analysis, thus providing rapid, simple, and inexpensive alternative method.

Acknowledgements: This study was supported by the Graduate School, Kasetsart University. We also would like to thank the Higher Education Research Promotion and National Research University Project of Thailand, office of the Higher Education Commission, National Research council of Thailand and Centre of Excellence-Oil palm Kasetsart University for partial supporting of this study.

\section{REFERENCES}

1. Meher LC, Naik SN, Das LM (2004) Metanolysis of Pongamia pinnata (karanja) oil for production of biodiesel. J Sci Ind Res 63, 913-8.

2. Bala M, Nag TN, Kumar S, Vyas M, Kumar A, Bhogal NS (2011) Proximate composition and fatty acid profile of Pongamia pinnata, a potential biodiesel crop. J Am Oil Chem Soc 88, 559-62.

3. Kesari V, Das A, Rangan L (2010) Physico-chemical characterization and antimicrobial activity from seed 
oil of Pongamia pinnata, a potential biofuel crop. Biomass Bioenerg 34, 108-15.

4. Vismaya, Sapna Eipeson W, Manjunatha JR, Srinivas P, Sindhu Kanya TC (2010) Extraction and recovery of karanjin: A value addition to karanja (Pongamia pinnata) seed oil. Ind Crop Prod 32, 118-22.

5. Quampah A, Huang ZR, Wu JG, Liu HY, Li JR, Zhu SJ, Shi CH (2012) Estimation of oil content and fatty acid composition in cottonseed kernel powder using near infrared reflectance spectroscopy. J Am Oil Chem Soc 89, 567-75.

6. Wu JG, Shi CH, Zhang HZ (2006) Study on developing calibration model of fat acid composition in intact rapeseed by near infrared reflectance spectroscopy. Spectros Spectral Anal 26, 259-62.

7. Tilman BL, Gorbet DW, Person G (2006) Prediction oleic and linoleic acid content of single peanut seedusing near-infrared reflectance spectroscopy. Crop Sci 46, 2121-6.

8. Sato T, Maw AA, Katsuta M (2003) NIR reflectance spectroscopic analysis of the FA composition in sesame (Sesamum indicum L.) seeds. J Am Oil Chem Soc 80, 1157-61.

9. Davrieux F, Allal F, Piombo G, Kelly B, Okulo JB, Thaim M, Diallo OB, Bouvet JM (2010) Near infrared spectroscopy for high-throughput characterization of shea tree (Vitellaria paradoxa) nut fat profiles. J Agr Food Chem 57, 7811-9.

10. Vaknin Y, Ghanim M, Samra S, Dvash L, Hendelsman E, Eisikowitch D, Samocha Y (2011) Predicting Jatropha curcas seed-oil content, oil composition and protein content using near-infrared spectroscopy-A quick and non-destructive method. Ind Crop Prod 34, 1029-34.

11. Kohel RJ (1998) Evaluation of near infrared reflectance for oil content of cotton seed. J Cotton Sci 2, 23-6.

12. Balabin RM, Safieva RZ (2011) Biodiesel classification by base stock type (vegetable oil) using near infrared spectroscopy data. Anal Chim Acta 689, 190-7.

13. Baptista P, Felizardo P, Menezes JC, Correia MJN (2008) Multivariate near infrared spectroscopy models for predicting the methyl esters content in biodiesel. Anal Chim Acta 607, 153-9.

14. Mukta N, Murthy IYLN, Sripal P (2009) Variability assessment in Pongamia pinnata (L.) Pierre germplasm for biodiesel traits. Ind Crop Prod 29, 536-40.

15. Pérez-Vich B, Velasco L, Fernández-Martínez JM (1998) Determination of seed oil content and fatty acid composition in sunflower through the analysis of intact seeds, husked seeds, meal and oil by nearinfrared reflectance spectroscopy. $J$ Am Oil Chem Soc 75, 547-55.

16. Kasemsumran S, Thanaphase W, Punsuvon V, Ozaki Y (2012) A feasibility study on non-destructive determination of oil content in palm fruits by visiblenear infrared spectroscopy. $J$ Near Infrared Spectros 20, 687-94. 